\title{
Chemotaxonomic Analyses of Bacteroides gracilis and Bacteroides ureolyticus and Reclassification of $B$. gracilis as Campylobacter gracilis comb. nov.
}

\author{
P. VANDAMME, ${ }^{1,2 *}$ M. I. DANESHVAR, ${ }^{3}$ F. E. DEWHIRST, ${ }^{4}$ B. J. PASTER,${ }^{4}$ \\ K. KERSTERS, ${ }^{1} \mathrm{H}$. GOOSSENS, ${ }^{2}$ AND C. W. MOSS ${ }^{3}$ \\ Laboratory of Microbiology, Universiteit Gent, B-9000 Ghent, ${ }^{1}$ and Department of Microbiology, University Hospital, \\ Antwerp, ${ }^{2}$ Belgium; Division of Bacterial and Mycotic Diseases, National Center for Infectious Diseases, \\ Centers for Disease Control and Prevention, Atlanta, Georgia 30333'; and Department of \\ Molecular Genetics, Forsyth Dental Center, Boston, Massachusetts 021154
}

\begin{abstract}
The cellular fatty acids, respiratory quinones, and proteins of the generically misnamed taxa Bacteroides gracilis and Bacteroides ureolyticus were analyzed and compared with the corresponding chemotaxonomic features of their closest relatives, the campylobacters. Our results and previously published data for genotypic and phenotypic characteristics were used in a polyphasic approach to reconsider the classification of these organisms. We transfer B. gracilis to the genus Campylobacter as Campylobacter gracilis comb. nov. B. ureolyticus can be considered a campylobacter on genotypic grounds; in contrast, the proteolytic metabolism and fatty acid components of this taxon exclude it from the genus Campylobacter. We prefer to consider this taxon a species incertae sedis pending the isolation and characterization of additional $B$. ureolyticus-like bacteria.
\end{abstract}

Clinical isolates of gram-negative bacilli that produce pitting or corroding growth on agar surfaces were first described by Henriksen (15) and Eiken (8). The name Bacteroides corrodens was proposed by Eiken (8) for these organisms, which were considered anaerobes. In fact, the Bacteroides corrodens group comprised several taxa (18). One subgroup contained facultatively anaerobic organisms having guanine-plus-cytosine $(\mathrm{G}+\mathrm{C})$ contents of 56 to $58 \mathrm{~mol} \%$, and this subgroup was subsequently named Eikenella corrodens (16). Strains belonging to this subgroup did not produce urease. Strains belonging to a second subgroup produced urease, had $\mathrm{G}+\mathrm{C}$ contents of 28 to $30 \mathrm{~mol} \%$, and were considered true anaerobes. This subgroup was referred to as "Bacteroides corrodens, anaerobic" and later was named Bacteroides ureolyticus (17), although its inclusion in the genus Bacteroides was dubious (40). B. ureolyticus strains have been isolated from patients with superficial ulcers, soft-tissue infections, nongonococcal nonchlamydial urethritis, and periodontal disease $(6,7,10,11)$. The pathogenicity of $B$. ureolyticus is difficult to assess because for the most part $B$. ureolyticus strains are recovered from mixed infections. Nevertheless, the presence of this organism in high numbers in mixed infections and the strong proteolytic activity which results in tissue destruction suggest that $B$. ureolyticus is pathogenic $(6,39)$.

The name Bacteroides gracilis was proposed by Tanner et al. for another group of agar-corroding bacteria (37). B. gracilis strains have $G+C$ contents of 44 to $46 \mathrm{~mol} \%$, and this species was originally also considered an anaerobic bacterium (37). $B$. gracilis strains have been isolated from gingival crevices and from visceral, head, and neck infections in humans (19). The association of $B$. gracilis with serious deep-tissue infections and its high level of antibiotic resistance suggest that this organism may be an important pathogen whose importance is underestimated (19).

For many years the genus Bacteroides has been known to be

${ }^{*}$ Corresponding author. Mailing address: Laboratorium voor Microbiologie, K.L. Ledeganckstraat 35, B-9000 Ghent, Belgium. Phone: 32.9.2645114. Fax: 32.9.2645346. phenotypically as well as genotypically extremely heterogeneous, and major taxonomic revisions of this genus have been proposed (32-34). Species previously known as Bacteroides species are now included in the genera Anaerorhabdus, Capnocytophaga, Fibrobacter, Megamonas, Mitsuokella, Porphyromonas, Prevotella, Rikenella, Ruminobacter, Sebaldella, and Tissierella (34). The taxonomic positions of several other species are still not known. rRNA homology studies have revealed that two of these other species, $B$. ureolyticus and $B$. gracilis, are closely related to members of the emended genus Campylobacter $(29,43)$. It has also been shown that, like campylobacters, B. ureolyticus and $B$. gracilis are microaerophils, not anaerobes (13). Both of these species were included in the family Campylobacteraceae together with the genera Campylobacter and Arcobacter by Vandamme and De Ley (41). Although genotypic data have clearly shown that $B$. ureolyticus and $B$. gracilis are generically misnamed, until now they have not been reclassified.

Below, respiratory quinone, protein, and fatty acid composition data for these organisms and for the biochemically similar organisms Wolinella succinogenes, Campylobacter rectus, and Campylobacter curvus are presented.

\section{MATERIALS AND METHODS}

Bacterial strains. The strains which we used and their sources are listed in Table 1. Bacteriological purity was checked by plating and examining living and Gram-stained cells.

Cellular fatty acid and isoprenoid quinone analyses. Cells for fatty acid and isoprenoid quinone analyses were grown on agar plates containing mycoplasma base broth supplemented with formate, fumarate, and hemin (30). The plates were incubated at $37^{\circ} \mathrm{C}$ for 4 days in an atmosphere containing approximately $80 \% \mathrm{~N}_{2}, 10 \% \mathrm{CO}_{2}$, and $10 \% \mathrm{H}_{2}$, and cells were removed with gentle scraping. Cellular fatty acids were liberated by saponification, processed, and analyzed as their methyl esters by using high-resolution capillary gas-liquid chromatography as described previously $(25,27)$. Isoprenoid quinones were extracted from 100 -mg portions of lyophilized cells and analyzed by reverse-phase highperformance liquid chromatography (RPHPLC) (24). The identities of individual fatty acids, aldehydes, dimethylacetals, and quinones were confirmed by mass spectrometry $(22,25)$.

PAGE of whole-cell proteins. Polyacrylamide gel electrophoresis (PAGE) of whole-cell proteins, a densitometric analysis, normalization and interpolation of the protein profiles, and a numerical analysis were performed as described previously $(47,48)$. All reference strains were grown for 3 days at $37^{\circ} \mathrm{C}$ on 
TABLE 1. Strains used and their sources

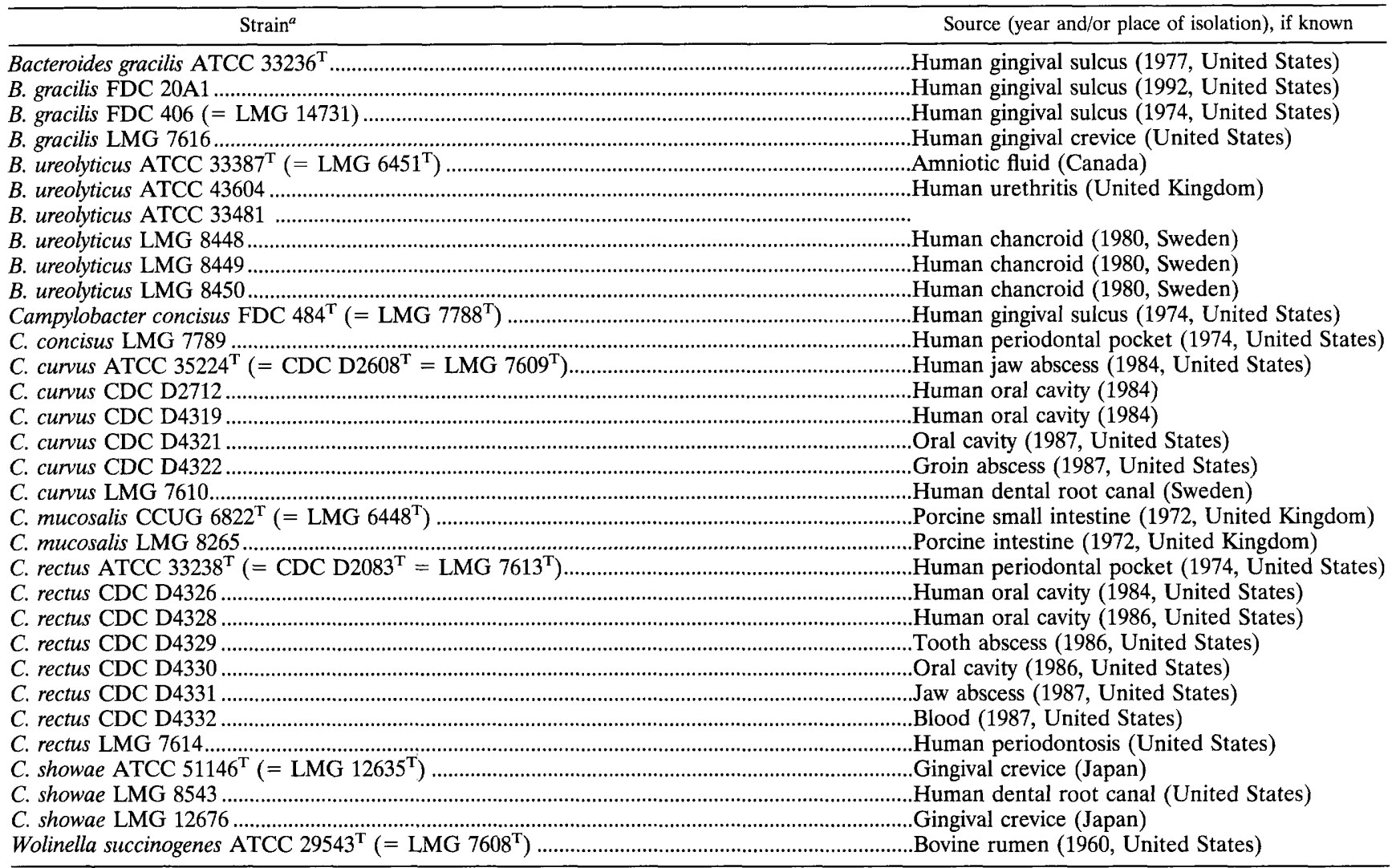

${ }^{a}$ ATCC, American Type Culture Collection, Rockville, Md.; CCUG, Culture Collection of the University of Göteborg Department of Clinical Bacteriology, University of Göteborg, Göteborg, Sweden; CDC, Centers for Disease Control and Prevention, Atlanta, Ga.; FDC, Forsyth Dental Center, Boston, Mass.; LMG, Culture Collection of the Laboratorium voor Microbiologie, University of Ghent, Ghent, Belgium.

Mueller-Hinton agar (catalog no. CM 337; Oxoid, Ltd., Basingstoke, United Kingdom) supplemented with $5 \%$ (vol/vol) horse blood and were incubated at 36 to $37^{\circ} \mathrm{C}$ in a microaerobic atmosphere containing approximately $5 \% \mathrm{O}_{2}, 3.5 \%$ $\mathrm{CO}_{2}, 7.5 \% \mathrm{H}_{2}$, and $84 \% \mathrm{~N}_{2}$

16S rRNA data analysis. The $16 \mathrm{~S} r \mathrm{RNA}$ sequences of the strains analyzed in this study have been described previously $(5,9,23,29,35)$. A program set for data entry, editing, sequence alignment, secondary-structure comparison, similarity matrix generation, and dendrogram construction for 16S rRNA data was written in Microsoft QuickBASIC for use on IBM PC and compatible computers (29). RNA sequences were entered and aligned as previously described (29). Our sequence database contains approximately 300 sequences determined in our laboratory and another 200 sequences obtained from GenBank or the Ribosomal Database Project (28). The reference strains used in the 16S rRNA analysis are shown in Table 2. Similarity matrices were constructed from the aligned sequences by using only those sequence positions at which $90 \%$ of the strains had data. The similarity matrices were corrected for multiple base changes by the method of Jukes and Cantor (20). Phylogenetic trees were constructed by using the neighbor-joining method of Saitou and Nei (31). Bootstrapping of neighborjoining trees was performed by using the program MEGA (21) with 500 resamplings and pairwise elimination of incomplete data.

Nucleotide sequence accession numbers. The GenBank nucleotide sequence and culture collection accession numbers for the strains used in the 16S rRNA sequence comparisons are shown in Table 2.

\section{RESULTS AND DISCUSSION}

Isoprenoid quinone analysis. Figure 1 shows an RPHPLC chromatogram of the isoprenoid quinone fraction from $B$. ureolyticus ATCC $33387^{\mathrm{T}}$ ( $\mathrm{T}=$ type strain). The retention times of the first two peaks, designated MK-5 and MK-6, were exactly the same as the retention times of standard MK-5 and MK-6, respectively. The retention time of the peak designated *MK-6 was exactly the same as the retention time of methylsubstituted menaquinone $6(2,[5$ or 8$]$-dimethyl-3-farnesyl- farnesyl-1,4-naphthoquinone) from Campylobacter fetus, the so-called thermoplasmaquinone $(2,25)$. Fractions corresponding to each of these three peaks were collected from RPHPLC preparations and analyzed by mass spectrometry. We confirmed that peaks MK-5 and MK- 6 were menaquinones since the mass spectrum of each peak had a base peak ion at $m / e 225$ and an intense ion at $m / e$ 187, representing the naphthoquinone nucleus $(2,25)$. The mass spectrum of the *MK-6 peak is shown in Fig. 2. This spectrum had a base peak ion at $m / e 239$ and a smaller ion at $m / e 201$, which is consistent with the presence of an additional methyl group on the naphthoquinone ring (2). This fragmentation pattern, together with a prominent molecular ion at $m / e 594$, confirmed that ${ }^{*} \mathrm{MK}-6$ was 2,[5 or 8]-dimethyl-3-farnesyl-farnesyl-1,4-naphthoquinone. Prominent molecular ions $\left(\mathrm{M}^{+}\right)$were observed at $m / e$ 512 for MK-5 and at $m / e 580$ for MK-6. The $\mathrm{M}^{+}$ions were verified by chemical ionization spectra, which had intense $(\mathrm{M}+1)^{+}$ions at the expected mass values of $m / e 513, m / e ~ 581$, and $m / e 595$ for MK-5, MK-6, and *MK-6, respectively.

All of the B. ureolyticus, B. gracilis, $C$. curvus, $C$. rectus, and $W$. succinogenes strains tested contained only menaquinones. The identities of the menaquinones and the relative amounts detected in each species are shown in Table 3. *MK-6 was present as a significant compound in all species and was the major menaquinone in all species except $W$. succinogenes, which contained MK-6 as its major component. All of the strains were regrown and retested for quinones, and the results were essentially identical. Moreover, the menaquinone patterns obtained for additional strains of each species (except $W$. 
TABLE 2. Strains used in 16S rRNA sequence studies and their accession numbers

\begin{tabular}{|c|c|c|}
\hline Taxon & Strain $^{a}$ & $\begin{array}{c}\text { GenBank } \\
\text { accession } \\
\text { no. }\end{array}$ \\
\hline \multicolumn{3}{|l|}{ Epsilon subclass of the Proteobacteria } \\
\hline Arcobacter butzleri & CCUG 10373 & L14626 \\
\hline Arcobacter cryaerophilus & CCUG $17801^{\mathrm{T}}$ & L14624 \\
\hline Arcobacter nitrofigilis & CCUG $15893^{\mathrm{T}}$ & L14627 \\
\hline Arcobacter skirrowii & CCUG $10374^{\mathrm{T}}$ & L14625 \\
\hline Bacteroides gracilis & ATCC $33236^{\mathrm{T}}$ & L04320 \\
\hline Bacteroides ureolyticus & ATCC $33387^{\mathrm{T}}$ & L04321 \\
\hline Campylobacter coli & CCUG $11238^{\mathrm{T}}$ & L04312 \\
\hline Campylobacter concisus & ATCC $33237^{\mathrm{T}}$ & L04322 \\
\hline Campylobacter curvus & ATCC $35224^{\mathrm{T}}$ & L04313 \\
\hline Campylobacter fetus subsp. fetus & ATCC $27374^{\mathrm{T}}$ & L04314 \\
\hline Campylobacter helveticus & NCTC $12570^{\mathrm{T}}$ & U03022 \\
\hline Campylobacyter hyointestinalis & ATCC $35217^{\mathrm{T}}$ & M65010 \\
\hline Campylobacter jejuni subsp. jejuni & CCUG $11284^{\mathrm{T}}$ & L04315 \\
\hline Campylobacter lari & CCUG $23947^{\mathrm{T}}$ & L04316 \\
\hline Campylobacter mucosalis & CCUG $6822^{\mathrm{T}}$ & L06978 \\
\hline Campylobacter mucosalis-like & CCUG 20705 & L14629 \\
\hline Campylobacter rectus & ATCC $33238^{\mathrm{T}}$ & L04317 \\
\hline Campylobacter showae & ATCC $51146^{\mathrm{T}}$ & L06974 \\
\hline $\begin{array}{l}\text { Campylobacter sputorum biovar } \\
\text { bubulus }\end{array}$ & ATCC 33491 & L04319 \\
\hline Campylobacter sp. & PGC 40-6AT & L04318 \\
\hline Campylobacter upsaliensis & CCUG $14913^{\mathrm{T}}$ & L14628 \\
\hline Helicobacter canis & NCTC $12739^{\mathrm{T}}$ & L13464 \\
\hline Helicobacter felis & ATCC $49179^{\mathbf{T}}$ & M37642 \\
\hline Helicobacter hepaticus & ATCC $51448^{\mathrm{T}}$ & U07574 \\
\hline Helicobacter mustelae & ATCC $43772^{\mathrm{T}}$ & M35048 \\
\hline Helicobacter pametensis & ATCC $51478^{\mathrm{T}}$ & M88147 \\
\hline Helicobacter pylori & ATCC $43504^{\mathrm{T}}$ & M88157 \\
\hline Wolinella succinogenes & ATCC $29543^{\mathrm{T}}$ & M88159 \\
\hline \multicolumn{3}{|l|}{ Delta subclass of the Proteobacteria } \\
\hline Desulfovibrio desulfuricans & ATCC 27774 & M34113 \\
\hline Myxococcus xanthus & MD207 & M34114 \\
\hline \multicolumn{3}{|l|}{ Gamma subclass of the Proteobacteria } \\
\hline Escherichia coli & & J01695 \\
\hline Pseudomonas aeruginosa & ATCC 25330 & M34133 \\
\hline \multicolumn{3}{|l|}{ Beta subclass of the Proteobacteria } \\
\hline Neisseria gonorrhoeae & NCTC $8375^{\mathrm{T}}$ & $\mathrm{X} 07714$ \\
\hline Eikenella corrodens & ATCC $23834^{\mathrm{T}}$ & M22512 \\
\hline \multicolumn{3}{|l|}{ Alpha subclass of the Proteobacteria } \\
\hline Agrobacterium tumefaciens & DSM 30105 & M11223 \\
\hline Rickettsia rickettsii & ATCC VR-891 & M21293 \\
\hline \multicolumn{3}{|l|}{ Bacteroides group } \\
\hline Prevotella loescheii & ATCC $15930^{\mathrm{T}}$ & L16481 \\
\hline Prevotella melaninogenica & ATCC $25845^{\mathrm{T}}$ & L16469 \\
\hline Bacteroides fragilis & ATCC $25285^{\mathrm{T}}$ & M11656 \\
\hline Bacteroides vulgatus & ATCC $8482^{\mathrm{T}}$ & M58762 \\
\hline Porphyromonas asaccharolytica & ATCC $25260^{\mathrm{T}}$ & L16490 \\
\hline Porphyromonas gingivalis & ATCC $33277^{\mathrm{T}}$ & L16492 \\
\hline \multicolumn{3}{|l|}{ Spirochetes } \\
\hline Borrelia burgdorferi & ATCC $35210^{\mathrm{T}}$ & M59293 \\
\hline Spirochaeta aurantia & ATCC $25082^{\mathrm{T}}$ & M57740 \\
\hline Treponema pallidum & Nichols & M34266 \\
\hline
\end{tabular}

${ }^{a}$ NCTC, National Collection of Type Cultures, London, United Kingdom; PGC, The Procter and Gamble Co. Cincinnati, Ohio. For other abbreviations see Table 1, footnote $a$.

${ }^{b}$ The 16S rRNA sequences of strains are available for electronic retrieval from the GenBank database under the accession numbers indicated. Because of cross-distribution of databases, these sequences should aiso be available from EMBL and DDBJ.

succinogenes, which contains only a single strain) were similar to the patterns obtained for the type strains shown in Table 2; there were only small quantitative differences among the strains of each species (data not shown). Thus, if the mena-

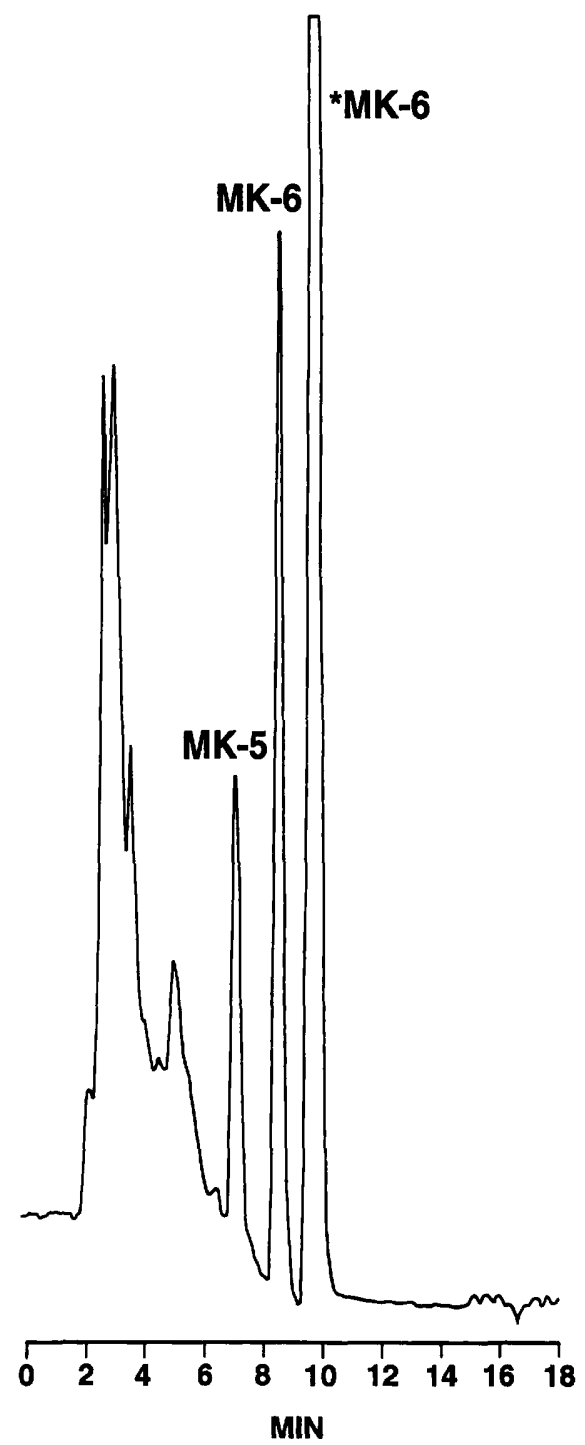

FIG. 1. RPHPLC chromatogram of menaquinones from B. ureolyticus ATCC $33387^{\mathrm{T}}$ analyzed on a $\mu$ Bondpack C18 reverse-phase column (300 by $3.9 \mathrm{~mm}$ ). The detector was set at $248 \mathrm{~nm}$. ${ }^{*} \mathrm{MK}-6$ is thermoplasmaquinone $(2,25)$.

quinone pattern of $W$. succinogenes is confirmed with additional strains, it will be possible to distinguish this organism from the other species listed in Table 2. It should be noted that the overall menaquinone patterns of all of the species listed in Table 2 are essentially identical to the patterns of one or more species belonging to the genus Campylobacter $(25,26)$. To our knowledge, *MK-6 is a unique menaquinone which has been found only in members of rRNA superfamily VI (43).

Cellular fatty acid analysis. The fatty acid compositions of all of the strains which we studied are shown in Table 4 . The fatty acid compositions of $C$. rectus and $B$. ureolyticus differed from the fatty acid compositions of $C$. curvus, $W$. succinogenes, and $B$. gracilis because $C$. rectus and $B$. ureolyticus lacked aldehydes and dimethylacetyls. $C$. curvus, $W$. succinogenes, and B. gracilis contained a 16-carbon dimethylacetyl (16:0 DMA) which was not present in $C$. rectus and $B$. ureolyticus. The overall fatty acid compositions of $C$. curvus and $W$. succinogenes were similar to each other and differed from the fatty acid composition of $C$. rectus by the presence of small amounts 


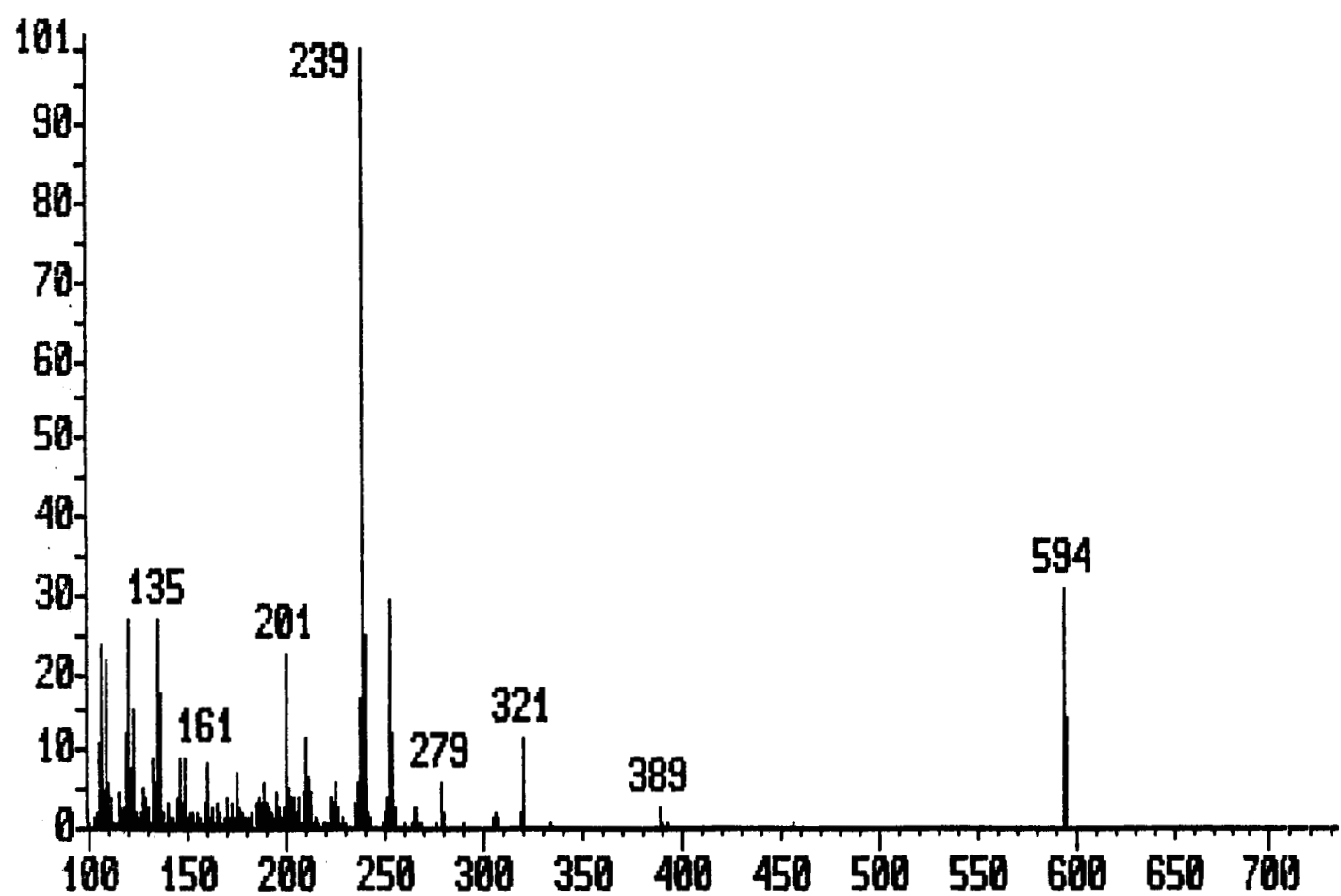

FIG. 2. Electron impact mass spectrum of ${ }^{*} \mathrm{MK}-6$ (2,[5 or 8]-dimethyl-3-farnesyl-farnesyl-1,4-naphthoquinone) isolated from B. ureolyticus ATCC 33387 ${ }^{\mathrm{T}}$.

of 16:0 DMA and 3-OH-16:0 (Table 4). The fatty acid composition of $B$. gracilis was clearly different, because this species contained significant amounts of a 16-carbon aldehyde (16:0 ALD) and an 18-carbon dimethylacetal (18:1 DMA). The presence of large amounts of $18: 1 \omega 7 \mathrm{c}$ and $3-\mathrm{OH}-16: 0$ and the low levels of $16: 1 \omega 7 \mathrm{c}$ distinguish $B$. ureolyticus from all other species (Table 4).

Our data confirm previous reports that $B$. gracilis has a fatty acid composition similar to that of campylobacters, whereas the fatty acid composition of $B$. ureolyticus is clearly distinct (1, $22,25)$.

Protein analysis. The cellular proteins of reference strains of $B$. ureolyticus, B. gracilis, C. curvus, C. rectus, and W. succinogenes were extracted and separated in polyacrylamide gels. The protein patterns are shown in Fig. 3, together with the protein patterns obtained for representative strains of other hydrogenrequiring Campylobacter species. Clearly, protein analysis is a useful method for differentiating these biochemically similar species. However, numerical comparisons of the protein elec-

TABLE 3. Menaquinone contents of the strains studied

\begin{tabular}{|c|c|c|c|}
\hline \multirow{2}{*}{ Strain } & \multicolumn{3}{|c|}{ Amt of ${ }^{a}$ : } \\
\hline & $\overline{\text { MK-5 }}$ & MK-6 & $\overline{{ }^{*} \mathrm{MK}-6^{b}}$ \\
\hline C. rectus ATCC $33238^{\mathrm{T}}$ & 1 & 1 & 4 \\
\hline C. curvus ATCC $35224^{\mathrm{T}}$ & $\mathrm{T}$ & 1 & 4 \\
\hline B. gracilis ATCC $33236^{\mathrm{T}}$ & $\mathrm{T}$ & 2 & 4 \\
\hline B. ureolyticus ATCC $33387^{\mathrm{T}}$ & 1 & 2 & 4 \\
\hline W. succinogenes ATCC $29543^{\mathrm{T}}$ & 1 & 4 & 2 \\
\hline
\end{tabular}

${ }^{a}$ The area of the major peak on each RPHPLC chromatogram was assigned a value of 4 , and the areas of the other peaks were related to this value (i.e., a value of 2 indicates that the area of a peak was $50 \%$ of the area of a peak with a value of $4 ; \mathrm{T}$ indicates that the area of a peak was less than $10 \%$ of the area of a peak with a value of 4 .

${ }^{b}$ *MK-6 is thermoplasmaquinone. trophoretic traces did not allow differentiation of species because of the extreme variability in the principal protein band region (Fig. 3) in some of the species (data not shown). It has been demonstrated previously that $B$. ureolyticus and several

TABLE 4. Cellular fatty acid compositions of the strains studied

\begin{tabular}{|c|c|c|c|c|c|}
\hline \multirow{2}{*}{ Fatty acid ${ }^{a}$} & \multicolumn{5}{|c|}{$\%$ of total fatty acids in: } \\
\hline & $\begin{array}{l}\text { C. rectus } \\
(n=8)^{b, c}\end{array}$ & $\begin{array}{l}\text { C. curvus } \\
(n=6)^{d}\end{array}$ & $\begin{array}{l}\text { B. gracilis } \\
(n=3)^{e}\end{array}$ & $\begin{array}{l}\text { B. ureolyticus } \\
(n=3)^{f}\end{array}$ & $\begin{array}{l}\text { W. succinogenes } \\
\quad(n=2)\end{array}$ \\
\hline $12: 0$ & $11^{g}$ & 7 & 10 & 5 & 6 \\
\hline $14: 0$ & 8 & 16 & 10 & 5 & 6 \\
\hline 16:0 ALD & ${ }^{h}$ & - & 12 & - & - \\
\hline $3-\mathrm{OH}-14: 0$ & 4 & 6 & 6 & 5 & 5 \\
\hline $16: 1 \omega 7 c$ & 8 & 9 & 8 & 1 & 18 \\
\hline $16: 0$ & 31 & 25 & 12 & 10 & 23 \\
\hline 16:1 DMA & - & - & 2 & - & - \\
\hline 16:0 DMA & - & 4 & 10 & - & 7 \\
\hline $18: 2$ & 8 & 3 & 一 & 一 & 6 \\
\hline 3-OH-16:0 & - & 1 & - & 5 & 1 \\
\hline $18: 1 \omega 9 c$ & 5 & 2 & 2 & 1 & 2 \\
\hline $18: 1 \omega 7 c$ & 18 & 22 & 14 & 61 & 22 \\
\hline 18:0 & 4 & 2 & 2 & 5 & 2 \\
\hline 18:1 DMA & - & - & 9 & - & 一 \\
\hline
\end{tabular}

${ }^{a}$ The number before the colon is the number of carbon atoms, and the number after the colon is the number of double bonds. ALD, aldehyde; DMA, dimethylacetal; $3-\mathrm{OH}$, a hydroxyl group occurs at carbon 3 ; $\omega$, double bond position from the hydrocarbon end of the chain; $c$, cis isomer.

${ }^{b} n$, number of strains tested.

${ }^{c}$ Strains ATCC $33238^{\mathrm{T}}$, CDC D2083 ${ }^{\mathrm{T}}$, CDC D4326, CDC D4328, CDC D4329, CDC D4330, CDC D4331, and CDC D4332.

${ }^{d}$ Strains ATCC $35224^{\mathrm{T}}$, CDC D2608 ${ }^{\mathrm{T}}$, CDC D2712, CDC D4319, CDC D4321, and CDC D4322.

${ }^{e}$ Strains ATCC $33236^{\mathrm{T}}$, FDC 20A1, and FDC 406

${ }^{f}$ Strains ATCC $33387^{\mathrm{T}}$, ATCC 43604 , and ATCC 33481.

$g$ Values are arithmetic means.

${ }^{h}-$, not detected or trace (less than $0.7 \%$ ). 


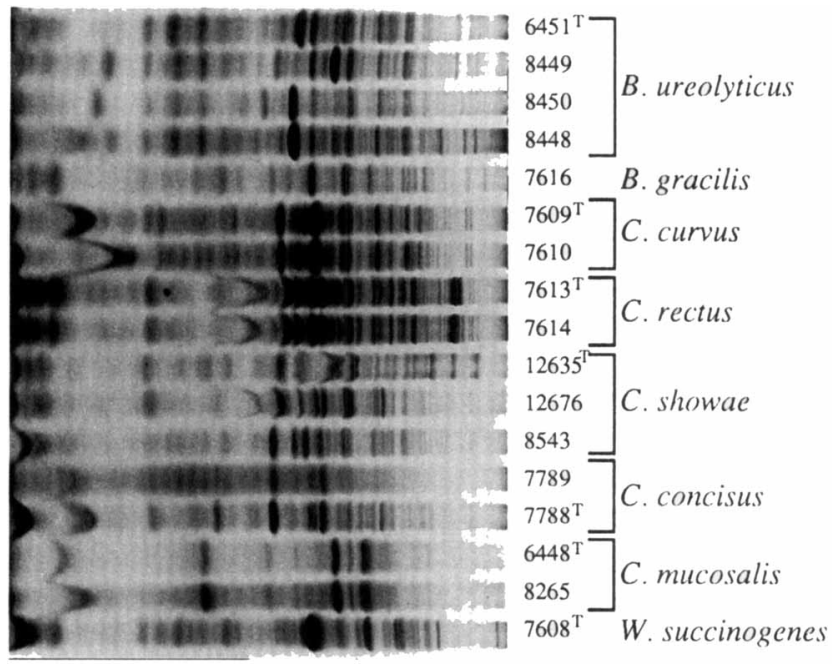

FIG. 3. Protein profiles of all strains examined and reference strains of hydrogen-requiring Campylobacter species. All strain numbers are LMG (Culture Collection of the Laboratorium voor Mikrobiologie, University of Ghent, Ghent, Belgium) numbers.

Campylobacter species are characterized by the presence of a variable dense-band region which is often useful for typing purposes $(4,39,40,42,44-46)$. Unknown strains belonging to taxa that produce such a variable dense-band region can be identified by omitting the variable-band region from the numerical analysis $(4,44)$ or by creating a database in which entries correspond to the various electrophoretic types within each of the species (42).

Phylogenetic position of $B$. gracilis and $B$. ureolyticus. A phylogenetic tree that includes representative strains of the different subgroups within the Proteobacteria, the genus Bacteroides and its relatives, and the spirochetes is shown in Fig. 4. This tree was generated from a similarity matrix based on a comparison of $16 \mathrm{~S}$ rRNA sequences at 1,421 base positions (data not shown). B. gracilis and B. ureolyticus fall in the epsilon subdivision of the Proteobacteria along with Campylobacter species, not in the genus Bacteroides, Prevotella, or Porphyromonas. In a more detailed analysis, $B$. gracilis and $B$. ureolyticus were compared with 26 reference Campylobacter, Arcobacter, Helicobacter, and Wolinella species. A similarity matrix based on sequence comparisons at 1,421 positions is shown in Table 5, and a phylogenetic tree based on this matrix is shown in Fig. 5. B. gracilis falls in the middle of a cluster containing five Campylobacter species, including C. rectus and Campylobacter sputorum. B. ureolyticus falls just outside the Campylobacter cluster. Bootstrapping of the neighbor-joining tree produced the values shown next to the nodes on the tree in Fig. 5 (values less than $50 \%$ are not shown). On the basis of its branching position, $B$. gracilis is clearly a member of the genus Campylobacter. A bootstrap value of $86 \%$ for the clade composed of the upper six species in the tree supports this conclusion. The phylogenetic position of $B$. ureolyticus is less certain. When the outgroup is changed, the position of $B$. ureolyticus occasionally changes to a position inside the Campylobacter cluster. A bootstrapping analysis also revealed that the Campylobacter clade separates from B. ureolyticus only $61 \%$ of the time. Thus, it is not clear from the 16S rRNA sequence analysis results whether $B$. ureolyticus branches outside the Campylobacter cluster (and should be placed in a new genus) or inside the Campylobacter cluster (and should be included in
(\% Difference)

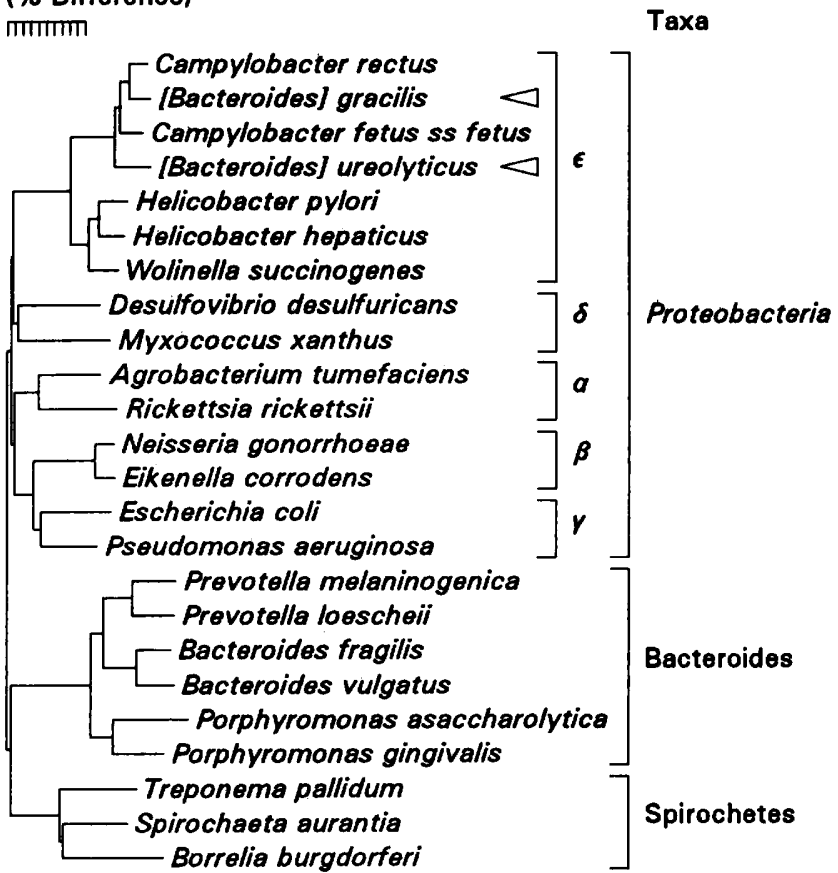

FIG. 4. Phylogenetic tree for members of the class Proteobacteria, Bacteroides species, and spirochetes. The positions of $[B$.$] gracilis and [B$.$] ureolyticus are$ indicated by arrowheads (the genus names are in brackets to indicate that these organisms are generically misnamed). The five divisions of the Proteobacteria are indicated by Greek letters. Scale bar $=10 \%$ difference in nucleotide sequences, as determined by measuring the lengths of the horizontal lines connecting two species.

the genus Campylobacter). B. ureolyticus falls in rRNA cluster I of rRNA superfamily VI $(41,43)$ and is clearly a member of the family Campylobacteraceae, which includes the genera Campylobacter and Arcobacter.

Classification of $\boldsymbol{B}$. gracilis and $\boldsymbol{B}$. ureolyticus. B. gracilis resembles campylobacters in almost all phenotypic characteristics; it is a microaerophilic, asaccharolytic organism which has biochemical characteristics that are the same as those of campylobacters $(13,37)$ and a DNA base ratio which is similar to the base ratios of campylobacters $(37,43)$. Biochemical differentiation of $B$. gracilis from some hydrogen-requiring campylobacters is difficult (36-38). In fact, only two characteristics distinguish $B$. gracilis from campylobacters, the absence of flagella and the absence of oxidase activity. Usually, campylobacters have a single flagellum at one or both ends of the cell (43); occasionally, nonmotile strains are found, whereas Campylobacter showae cells have bundles of two to five flagella (9). Clearly, the absence of a flagellar sheath (12) is taxonomically relevant in the genus Campylobacter, whereas the number of flagella is not. Similar findings have been reported for the genus Helicobacter. Different Helicobacter species may have different numbers of flagella (single flagella or tufts of flagella that are distributed polarly or laterally) $(12,43)$. However, the flagella of all of these species are sheathed $(12,43)$. Thus again, the number or position of the flagella is less significant than the flagellar structure. The second biochemical characteristic that differentiates $B$. gracilis from campylobacters is the absence of measurable oxidase activity. The pattern of cytochromes found in B. gracilis resembles the pattern reported for Campylobacter species in that $B$. gracilis possesses cytochromes $b$ and $c$ and CO-binding cytochrome $c$ and does not possess detectable type $a$ and $d$ cytochromes (14). Oxidase activity as 


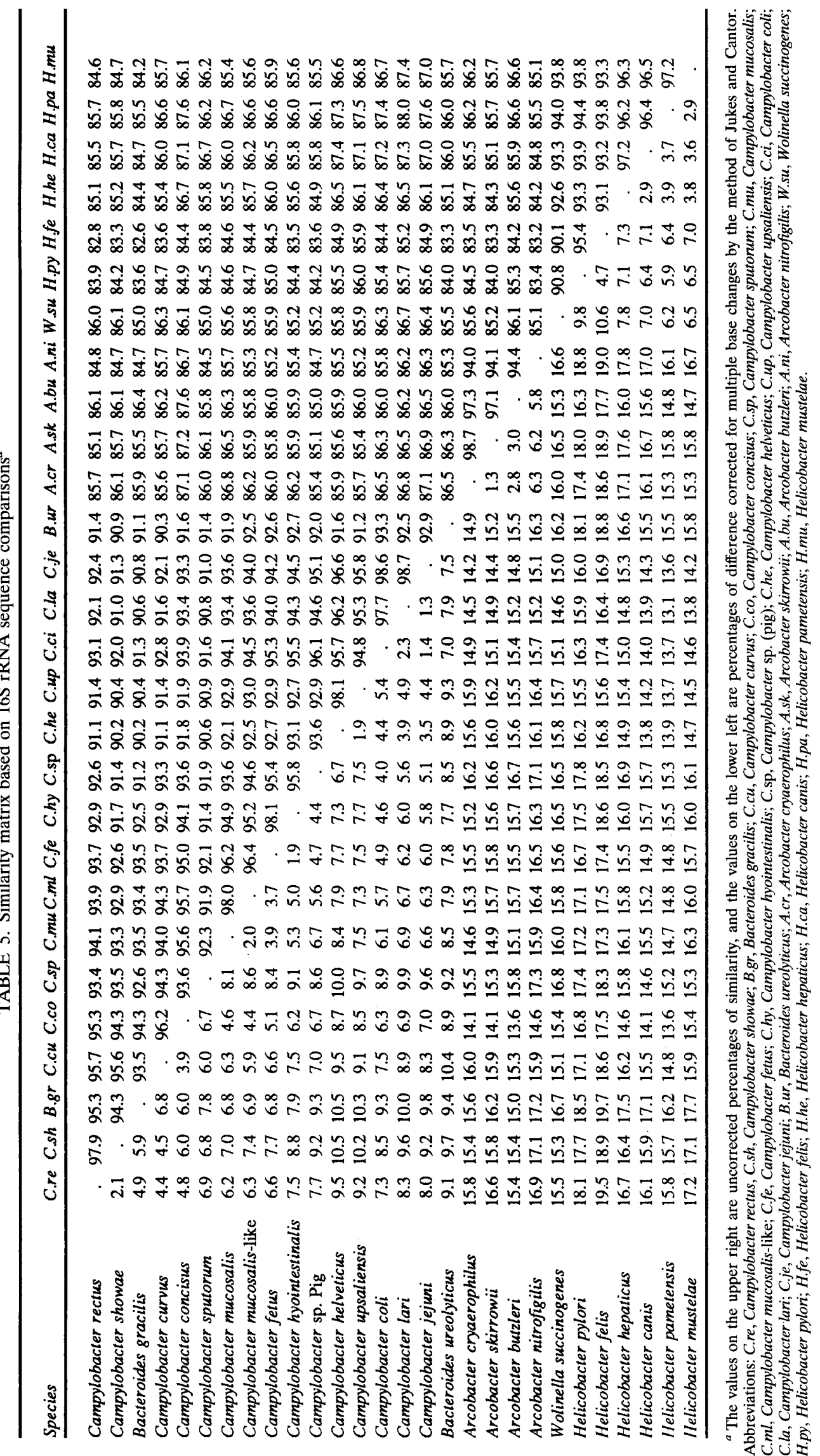




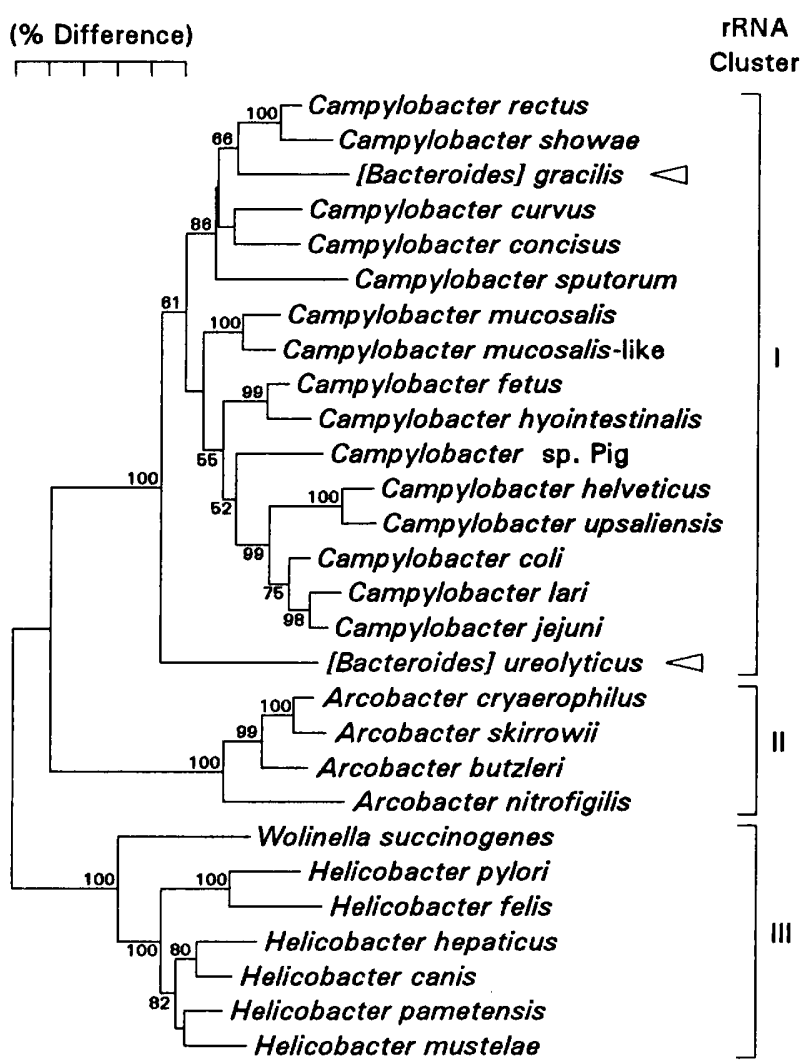

FIG. 5. Phylogenetic tree for the epsilon subdivision of the Proteobacteria. The positions of $[B$.] gracilis and $[B$.] ureolyticus are indicated by arrowheads (the genus names are in brackets to indicate that these organisms are generically misnamed). The epsilon subdivision of the Proteobacteria corresponds to rRNA superfamily VI. The rRNA clusters within superfamily VI are the clusters described previously (43). Scale bar $=5 \%$ difference in nucleotide sequences, as determined by measuring the lengths of the horizontal lines connecting two species. The values to the left of the nodes are the percentages of times that the strains to the right of the nodes occur together by bootstrapping. Bootstrapping values less than $50 \%$ are not shown.

determined by the Kovács test is associated with cytochrome $c$ and oxygen respiration, which are both present in $B$. gracilis and campylobacters. Possible explanations for the fact that oxidase activity is not detected are (i) that the reagent (tetramethylphenylenediamine) cannot penetrate the cellular membranes, and (ii) that a low-potential cytochrome $c$ that cannot oxidize this reagent is present (14). However, it is unlikely that the absence of measurable oxidase activity is caused by a fundamental metabolic difference between $B$. gracilis and Campylobacter species.

In summary, $B$. gracilis is a Campylobacter species on the basis of its genotypic and phenotypic characteristics and has the same human oral niche as several Campylobacter species. We conclude that $B$. gracilis is a nonmotile campylobacter, and below we propose that this taxon should be transferred to the genus Campylobacter. The genus description of Campylobacter has to be emended to include species with multiple flagella (9) and species without flagella.

Reclassification of $B$. ureolyticus is not straightforward. $B$. ureolyticus resembles campylobacters in its respiratory quinone content (Table 3) and in its DNA base ratio (43). These findings are not unexpected since a $16 \mathrm{~S}$ rRNA sequence analysis revealed that these taxa are close relatives, while respiratory quinone compositions characterize taxonomic units at the deep phylogenetic level rather than the fine taxonomic level (3). B. ureolyticus differs from campylobacters in its fatty acid composition, its proteolytic metabolism, and its ability to hydrolyze urea (only a few atypical Campylobacter lari strains have been reported to hydrolyze urea [43]). Furthermore, the majority of $B$. ureolyticus strains are isolated from patients with superficial ulcers, soft-tissue infections, and urethritis and are therefore unlikely to be confused with campylobacters. The group of dental $B$. ureolyticus-like isolates can be readily differentiated from oral campylobacters by their ability to hydrolyze urea and by their proteolytic activity. However, this group of dental isolates has been shown to be heterogeneous, and the taxonomic structure and position of this taxon will require further investigation (7). Obviously, including $B$. ureolyticus in the genus Campylobacter or in a new genus is arbitrary. Including it in the genus Campylobacter would considerably increase the phenotypic heterogeneity of this genus, but excluding it from the genus Campylobacter would result in the creation of a monotypic taxon which differed from the genus Campylobacter only in the ability to digest casein and gelatin and in the presence of urease activity. While $B$. ureolyticus is clearly a member of the family Campylobacteraceae, we do not believe that it should be renamed at this time and prefer to consider this taxon a species incertae sedis pending the isolation and a thourough taxonomic characterization of additional $B$. ureolyticus-like bacteria.

Description of Campylobacter gracilis comb. nov. The description of Campylobacter gracilis (basonym, Bacteroides gracilis Tanner, Badger, Lai, Listgarten, Visconti, and Socransky 1981 ) is the same as that given previously for B. gracilis (37). The type strain is strain ATCC 33236.

\section{ACKNOWLEDGMENTS}

P.V. is indebted to the National Fund for Scientific Research (Belgium) for a position as a postdoctoral research fellow.

We are grateful to T. O. MacAdoo, Department of Foreign Languages, Virginia Polytechnic Institute and State University, Blacksburg, for helpful discussions concerning the nomenclature of bacteria.

\section{REFERENCES}

1. Brondz, I., and I. Olsen. 1991. Multivariate analyses of cellular fatty acids in Bacteroides, Prevotella, Porphyromonas, Wolinella, and Campylobacter spp. J. Clin. Microbiol. 29:183-189.

2. Carlone, G. M., and F. A. L. Anet. 1983. Detection of menaquinone- 6 and a novel methyl-substituted menaquinone-6 in Campylobacter jejuni and Campylobacter fetus subsp. fetus. J. Gen. Microbiol. 129:3385-3393.

3. Collins, M. D., and D. Jones. 1981. Distribution of isoprenoid quinone structural types in bacteria and their taxonomic implications. Microbiol. Rev. 45:316-354.

4. Costas, M. 1992. Classification, identification, and typing of bacteria by the analysis of their one-dimensional polyacrylamide gel electrophoretic protein patterns, p. 351-408. In A. Chambrach, M. J. Dunn, and B. J. Radola (ed.), Advances in electrophoresis, vol. 5. VCH Verlagsgesellschaft, Weinheim, Germany.

5. Dewhirst, F. E., C. Seymour, G. J. Fraser, B. J. Paster, and J. G. Fox. 1994. Phylogeny of Helicobacter isolates from bird and swine feces and description of Helicobacter pametensis sp. nov. Int. J. Syst. Bacteriol. 44:553-560.

6. Duerden, B. I., A. Eley, L. Goodwin, J. T. Magee, J. M. Hindmarch, and K. W. Bennett. 1989. A comparison of Bacteroides urealyticus isolates from different clinical sources. J. Med. Microbiol. 29:63-73.

7. Duerden, B. I., L. Goodwin, and T. C. A. O'Neil. 1987. Identification of Bacteroides species from adult periodontal disease. J. Med. Microbiol. 24:133-137.

8. Eiken, M. 1958. Studies on an anaerobic rod-shaped, gram negative microorganism: Bacteroides corrodens n. sp. Acta Pathol. Microbiol. Scand. 43:404-416.

9. Etoh, Y., F. E. Dewhirst, B. J. Paster, A. Yamamoto, and N. Goto. 1993. Campylobacter showae sp. nov., isolated from the human oral cavity. Int. J. Syst. Bacteriol. 43:631-639.

10. Fontaine, E. A. R., S. P. Borriello, D. Taylor-Robinson, and H. A. Davies. 1984. Characteristics of a gram-negative anaerobe isolated from men with nongonococcal urethritis. J. Med. Microbiol. 17:129-140. 
11. Fontaine, E. A. R., T. N. Bryant, D. Taylor-Robinson, S. P. Borriello, and H. A. Davies. 1986. A numerical taxonomic study of anaerobic gram-negative bacilli classified as Bacteroides ureolyticus isolated from patients with nongonococcal urethritis. J. Gen. Microbiol. 132:3137-3146.

12. Han, Y.-H., R. M. Smibert, and N. R. Krieg. 1989. Occurrence of sheathed flagella in Campylobacter cinaedi and Campylobacter fennelliae. Int. J. Syst. Bacteriol. 39:488-490.

13. Han, Y.-H., R. M. Smibert, and N. R. Krieg. 1991. Wolinella recta, Wolinella curva, Bacteroides ureolyticus, and Bacteroides gracilis are microaerophils, not anaerobes. Int. J. Syst. Bacteriol. 41:218-222.

14. Han, Y.-H., R. M. Smibert, and N. R. Krieg. 1992. Cytochrome composition and oxygen-dependent respiration-driven proton translocation in Wolinella curva, Wolinella recta, Bacteroides ureolyticus, and Bacteroides gracilis. Can. J. Microbiol. 38:104-110.

15. Henriksen, S. D. 1948. Studies in gram-negative anaerobes: gram-negative anaerobic rods with spreading colonies. Acta Pathol. Microbiol. Scand. 25:368-375.

16. Jackson, F. L., and Y. E. Goodman. 1972. Transfer of the facultatively anaerobic organism Bacteroides corrodens Eiken to a new genus, Eikenella. Int. J. Syst. Bacteriol. 22:73-77.

17. Jackson, F. L., and Y. E. Goodman. 1978. Bacteroides ureolyticus, a new species to accommodate strains previously identified as "Bacteroides corrodens, anaerobic.” Int. J. Syst. Bacteriol. 28:197-200.

18. Jackson, F. L., Y. E. Goodman, F. R. Bel, P. C. Wong, and R. L. S. Whitehouse. 1971. Taxonomic status of facultative and strictly anaerobic "corroding bacilli" that have been classified as Bacteroides corrodens. J. Med. Microbiol. 4:171-184.

19. Johnson, C. C., J. F. Reinhardt, M. A. C. Edelstein, M. E. Mulligan, W. L. George, and S. M. Finegold. 1985. Bacteroides gracilis, an important anaerobic bacterial pathogen. J. Clin. Microbiol. 22:799-802.

20. Jukes, T. H., and C. R. Cantor. 1969. Evolution of protein molecules, p 21-132. In H. N. Munro (ed.), Mammalian protein metabolism, vol. 3 . Academic Press, Inc., New York.

21. Kumar, S., K. Tamura, and M. Nei. 1993. MEGA: molecular evolutionary genetic analysis, version 1.0. The Pennsylvania State University, University Park.

22. Lambert, M. A., C. M. Patton, T. J. Barrett, and C. W. Moss. 1987. Differentiation of Campylobacter and Campylobacter-like organisms by cellular fatty acid composition. J. Clin. Microbiol. 25:706-713.

23. Linton, D., F. E. Dewhirst, J. Clewley, R. J. Owen, A. P. Burnens, and J. Stanley. 1994. Two types of 16S rRNA gene are found in Campylobacter helveticus: analysis, applications and characterization of the intervening sequence found in some strains. Microbiology 140:847-855.

24. Moss, C. W., and G. O. Guerrant. 1983. Separation of bacterial ubiquinones by reverse-phase high-pressure liquid chromatography. J. Clin. Microbiol. 18:15-17.

25. Moss, C. W., A. Kai, M. A. Lambert, and C. Patton. 1984. Isoprenoid quinone content and cellular fatty acid composition of Campylobacter species. J. Clin. Microbiol. 19:772-776.

26. Moss, C. W., M. A. Lambert-Fair, M. A. Nicholson, and G. O. Guerrant. 1990. Isoprenoid quinones of Campylobacter cryaerophila, $C$. cinaedi, $C$. fennelliae, C. hyointestinalis, C. pylori, and "C. upsaliensis." J. Clin. Microbiol. 28:395-397.

27. Moss, C. W., P. L. Wallace, D. G. Hollis, and R. E. Weaver. 1988. Cultural and chemical characterization of CDC groups EO-2, M5, and M6, Moraxella (Moraxella) species, Oligella urethralis, Acinetobacter species, and Psychrobacter immobilis. J. Clin. Microbiol. 26:484-492.

28. Olsen, G. J., R. Overbeek, N. Larsen, T. L. Marsh, M. J. McCaughey, M. A. Maciukenas, W.-M. Kuan, T. J. Macke, Y. Xing, and C. R. Woese. 1992. The Ribosomal Database Project. Nucleic Acids Res. 20:2199-2200.

29. Paster, B. J., and F. E. Dewhirst. 1988. Phylogeny of campylobacters, wolinellas, Bacteroides gracilis, and Bacteroides ureolyticus by $16 \mathrm{~S}$ ribosomal ribonucleic acid sequencing. Int. J. Syst. Bacteriol. 38:56-62.

30. Paster, B. J., and G. J. Gibbons. 1986. Chemotactic response to formate by Campylobacter concisus and its potential role in gingival colonization. Infect. Immun. 52:378-383.
31. Saitou, N., and M. Nei. 1987. The neighbor-joining method: a new method for reconstructing phylogenetic trees. Mol. Biol. Evol. 4:406-425.

32. Shah, H. N., and M. D. Collins. 1988. Proposal for reclassification of Bacteroides asaccharolyticus, Bacteroides gingivalis, and Bacteroides endodontalis in a new genus, Porphyromonas. Int. J. Syst. Bacteriol. 38:128-131.

33. Shah, H. N., and M. D. Collins. 1989. Proposal to restrict the genus Bacteroides (Castellani and Chalmers) to Bacteroides fragilis and closely related species. Int. J. Syst. Bacteriol. 39:85.

34. Shah, H. N., and M. D. Collins. 1990. Prevotella, a new genus to include Bacteroides melanogenicus and related species formerly classified in the genus Bacteroides. Int. J. Syst. Bacteriol. 40:205-208.

35. Stanley, J., D. Linton, A. P. Burnens, F. E. Dewhirst, R. J. Owen, A. Porter, S. L. W. On, and M. Costas. 1993 . Helicobacter canis sp. nov., a new species from dogs: an integrated study of phenotype and genotype. J. Gen. Microbiol. 139:2495-2504

36. Tanner, A. C. R. 1986. Characterization of Wolinella spp., Campylobacter concisus, Bacteroides gracilis, and Eikenella corrodens by polyacrylamide gel electrophoresis. J. Clin. Microbiol. 24:562-565.

37. Tanner, A. C. R., S. Badger, C.-H. Lai, M. A. Listgarten, R. A. Visconti, and S. S. Socransky. 1981. Wolinella gen. nov., Wolinella succinogenes (Vibrio succinogenes Wolin et al.) comb. nov., and description of Bacteroides gracilis sp. nov., Wolinella recta sp. nov., Campylobacter concisus sp. nov., and Eikenella corrodens from humans with periodontal disease. Int. J. Syst. Bacteriol. 31:432-445.

38. Tanner, A. C. R., J. L. Dzink, J. L. Ebersole, and S. S. Socransky. 1987. Wolinella recta, Campylobacter concisus, Bacteroides gracilis and Eikenella corrodens from periodontal lesions. J. Periodontal Res. 22:327-330.

39. Taylor, A. J., M. Costas, and R. J. Owen. 1987. Numerical analysis of electrophoretic protein patterns of Bacteroides ureolyticus clinical isolates. J. Clin. Microbiol. 25:660-666.

40. Taylor, A. J., C. A. Dawson, and R. J. Owen. 1986. The identification of Bacteroides ureolyticus from patients with non-gonococcal urethritis by conventional biochemical tests and by DNA and protein analyses. J. Med. Microbiol. 21:109-116.

41. Vandamme, P., and J. De Ley. 1991. Proposal for a new family, Campylobacteraceae. Int. J. Syst. Bacteriol. 41:451-455.

42. Vandamme, P., D. Dewettinck, and K. Kersters. 1992. Application of numerical analysis of electrophoretic protein profiles for the identification of thermophilic campylobacters. Syst. Appl. Microbiol. 15:402-408.

43. Vandamme, P. E. Falsen, R. Rossau, B. Hoste, P. Segers, R. Tytgat, and J. De Ley. 1991. Revision of Campylobacter, Helicobacter, and Wolinella taxonomy: emendation of generic descriptions and proposal of Arcobacter gen. nov. Int. J. Syst. Bacteriol. 41:88-103.

44. Vandamme, P., B. Pot, E. Falsen, K. Kersters, and J. De Ley. 1990 . Intraand interspecific relationships of veterinary campylobacters revealed by numerical analysis of electrophoretic protein profiles and DNA:DNA hybridizations. Syst. Appl. Microbiol. 13:295-303.

45. Vandamme, P., B. Pot, and K. Kersters. 1991. Differentiation of campylobacters and Campylobacter-like organisms by numerical analysis of onedimensional electrophoretic protein patterns. Syst. Appl. Microbiol. 14:5766 .

46. Vandamme, P., M. Vancanneyt, B. Pot, L. Mels, B. Hoste, D. Dewettinck, L. Vlaes, C. Van Den Borre, R. Higgins, J. Hommez, K. Kersters, J.-P. Butzler, and H. Goossens. 1992. Polyphasic taxonomic study of the emended genus Arcobacter with Arcobacter butzleri comb. nov. and Arcobacter skirrowii sp. nov., an aerotolerant bacterium isolated from veterinary specimens. Int. J. Syst. Bacteriol. 42:344-356.

47. Vauterin, L., J. Swings, and K. Kersters. 1991. Grouping of Xanthomonas campestris pathovars by SDS-PAGE of proteins. J. Gen. Microbiol. 137: 1677-1687.

48. Vauterin, L., P. Yang, B. Hoste, M. Vancanneyt, E. L. Civerolo, J. Swings, and K. Kersters. 1991. Differentiation of Xanthomonas campestris pv. citri strains by sodium dodecyl sulfate-polyacrylamide gel electrophoresis of proteins, fatty acid analysis, and DNA-DNA hybridization. Int. J. Syst. Bacteriol. 41:535-542. 